\title{
A PARAMETER-BASED OSTROWSKI TYPE INEQUALITY ON TIME SCALES WITH $k$ POINTS FOR FUNCTIONS HAVING BOUNDED SECOND DERIVATIVES
}

\author{
Seth Kermausuor And Eze R. NwaEZE
}

\begin{abstract}
In this paper, we introduce a parameter $\lambda \in[0,1]$, and obtain a generalization of the Ostrowski type inequality on time scales for $k$ points for functions whose second derivatives are bounded. Our results generalize some results in the literature and thereby, injects into the mathematical community some inequalities which we hope can be used to approximate the integral of a function in applied mathematics and/or mathematical physics. In addition, we apply our main theorem to the continuous, discrete, and quantum calculus to derive more inequalities in this direction.
\end{abstract}

Mathematics subject classification (2010): 26D10. 26D15, 54C30.

Keywords and phrases: Montgomery identity, Ostrowski's inequality, parameter, time scales, bounded second derivatives.

\section{REFERENCES}

[1] M. Bohner And A. Peterson, Dynamic equations on time scales, Birkhäuser Boston, Boston, MA, (2001).

[2] M. Bohner And A. Peterson, Advances in Dynamic Equations on Time Series, Birkhäuser Boston, Boston, MA, (2003).

[3] M. Bohnerand T. Matthews, Ostrowski inequalities on time scales, J. Inequal. Pure and Appl. Math. 9, (2008), Art. 6.

[4] S. S. Dragomir, Grüss inequality in inner product spaces, The Aust. Math. Soc. Gazette., 26, 2 (1999), 66-70.

[5] S. Hilger, Ein Maßkettenkalkül mit Anwendung auf Zentrumsmannigfaltigkeiten, Ph. D. thesis, Universität Würzburg, Würzburg, Germany, (1988).

[6] B. Karpuz And U. M. ÖZKan, Ostrowski Inequality on time scales, J. Inequal. Pure and Appl. Math. 9, 4 (2008), Art. 112.

[7] S. KeRMAUSUOR, Ostrowski type and Ostrowski-Gruss type inequalities for vector-valued functions with $k$ points via a parameter, Adv. Inequal. Appl. 2018, (2018), Article ID 10.

[8] S. Kermausuor, E. R. Nwaeze And D. F. M. Torres, Generalized weighted Ostrowski and Ostrowski-Grüss type inequalities on time scales via a parameter function, J. Math. Inequal. 11, 4 (2017), 1185-1199.

[9] W. J. LIU AND Q. A. NGô, A generalization of Ostrowski inequality on time scales for $k$ points, Appl. Math. Comput. 203, 2 (2008), 754-760.

[10] W. J. LIU, Q. A. NGÔ AND W. B. CHEN, A perturbed Ostrowski-type inequality on time scales for $k$ points for functions whose second derivatives are bounded, J. Inequal. Appl. 2008, (2008), Article ID 597241, 12 pages.

[11] W. J. LiU AND Q. A. NGô, An Ostrowski type inequality on time scales for functions whose second derivatives are bounded, Inequality Theory and Applications, Nova Science Pub Inc. 6, (2010), 133 141. ISBN: 978-1616686253.

[12] W. J. Liu, A. Tuna And Y. Jiang, On weighted Ostrowski type, Trapezoid type, Grüss type and Ostrowski-Grüss like inequalities on time scales, Appl. Anal. 93, 3 (2014), 551-571. 
[13] W. J. LiU, A. TunA AND Y. JiAng, New weighted Ostrowski and Ostrowski-Grüss type inequalities on time scales, An. Ştiinţ. Univ. Al. I. Cuza laşi. Mat. (N. S.), 60, 1 (2014), 57-76.

[14] E. R. NwAEZE, A new weighted Ostrowski type inequality on arbitrary time scale, J. King Saud Uni. Sci. 29, 2 (2017), 230-234.

[15] E. R. NWAEZE, Time scale versions of the Ostrowski-Grüss type inequality with a parameter function, J. Math. Inequal. 12, 2 (2018), 531-543.

[16] E. R. NWAEZE, Generalized weighted trapezoid and Grüss type inequalities on time scales, Aust. J. Math. Anal. Appl. 11, 1 (2017), Art. 4.

[17] E. R. NwaEZE And S. Kermausuor, New Bounds of Ostrowski-Grüss type inequality for $(k+1)$ points on time scales, Int. J. Anal. Appl. 15, 2 (2017), 211-221.

[18] E. R. Nwaeze, S. Kermausuor And A. M. TAMERU, New time scale generalizations of the Ostrowski-Grüss type inequality for $k$ points, J. Inequal. Appl. 2017:245, (2017).

[19] E. R. NWAEZE AND A. M. TAMERU, On weighted Montgomery identity for $k$ points and its associates on time scales, Abstr. App. Anal. (2017), Art. ID 5234181.

[20] A. TunA AND D. Daghan, Generalization of Ostrowski and Ostrowski-Grüss type inequalities on time scales, Comput. Math. Appl. 60, (2010), 803-811.

[21] G. XU AND Z. B. FAnG, A Generalization of Ostrowski type inequality on time scales with $k$ points, J. Math. Inequal. 11, 1 (2017), 41-48. 